\title{
Interpreting biochemical control response rates with first- generation somatostatin analogues in acromegaly
}

\author{
Annamaria Colao $^{1} \cdot$ Renata S. Auriemma $^{1} \cdot$ Rosario Pivonello $^{1} \cdot$ Leandro Kasuki $^{2}$. \\ Mônica R. Gadelha ${ }^{2}$
}

Published online: 30 October 2015

(C) The Author(s) 2015

\begin{abstract}
Context The somatostatin analogues octreotide LAR and lanreotide Autogel have been evaluated for the treatment of acromegaly in numerous clinical trials, with considerable heterogeneity in reported biochemical response rates. This review examines and attempts to account for these differences in response rates reported in the literature.

Evidence acquisition PubMed was searched for Englishlanguage studies of a minimum duration of 24 weeks that evaluated $\geq 10$ patients with acromegaly treated with octreotide LAR or lanreotide Autogel from 1990 to March 2015 and reported GH and/or IGF-1 data as the primary objective of the study.

Evidence synthesis Of the 190 clinical trials found, 18 octreotide LAR and 15 lanreotide Autogel studies fulfilled the criteria for analysis. It is evident from the protocols of these studies that multiple factors are capable of impacting on reported response rates. Prospective studies reporting an intention-to-treat analysis that evaluated medically naïve patients and used the composite endpoint of both GH and IGF-1 control were associated with lower response rates. The use of non-composite biochemical control endpoints, heterogeneous patient populations, analyses that exclude treatment non-responders, assay variability and prior responsiveness to medical therapy are just a few of the
\end{abstract}

Annamaria Colao

colao@unina.it

1 Dipartimento di Medicina Clinica e Chirurgia, Università Federico II di Napoli, Via S Pansini 5, 80131 Naples, Italy

2 Endocrine Unit, Hospital Universitário Clementino Fraga Filho, Universidade Federal do Rio de Janeiro, Rio de Janeiro, Brazil factors identified that likely contribute to higher success rates.

Conclusions The wide range of reported response rates with somatostatin analogues may be confusing and could lead to misinterpretation by both the patient and the physician in certain situations. Understanding the factors that potentially drive the variation in response rates should allow clinicians to better gauge treatment expectations in specific patients.

Keywords Acromegaly - Octreotide - Lanreotide · Pasireotide $\cdot$ Somatostatin analogue $\cdot$ Response rate

\section{Introduction}

Acromegaly is almost always caused by a growth hormone (GH)-secreting pituitary tumor and is associated with increased morbidity and mortality [1]. Prompt treatment is essential in order to abrogate potentially life-threatening complications. Clinical practice guidelines advocate a multi-component therapeutic approach which includes lowering of both serum GH and insulin-like growth factor 1 (IGF-1) levels, tumor volume reduction, and amelioration of signs, symptoms and co-morbidities [1-3]. Somatostatin analogues, such as long-acting formulations of octreotide (octreotide LAR) and lanreotide (lanreotide Autogel), are recommended as first-line medical treatment for patients with acromegaly [2]. Octreotide LAR and lanreotide Autogel have been evaluated for the treatment of acromegaly in numerous clinical trials, with heterogeneity in reported biochemical response rates [4]. Studies of octreotide LAR prior to 2006 suggested that $50-70 \%$ of patients with acromegaly respond to octreotide LAR [5-9]. In line with this, in a meta-analysis by Freda et al. [10] 
examining trials published before 2004, overall response rates for octreotide LAR were determined to be $57 \%$ in terms of GH control and $67 \%$ in terms of normalization of IGF-1. Additional studies of octreotide LAR [11, 12] and lanreotide Autogel $[13,14]$ published shortly after reported biochemical response rates as high as $70-80 \%$. More recently, however, response rates in prospective clinical trials of octreotide LAR, lanreotide Autogel and the multireceptor-targeted somatostatin analogue pasireotide have been substantially lower (17-41\%) [15-23].

The purpose of this review is to examine and attempt to account for the differences in response rates reported in the literature for first-generation somatostatin analogues. Where appropriate, examples will be provided to illustrate how various factors may affect reported outcomes. Clinical study results will also be discussed in order to help practitioners treating patients with acromegaly put results from published clinical trials into context.

\section{Selection of studies for review}

PubMed was searched for English-language studies evaluating patients with acromegaly treated with octreotide LAR or lanreotide Autogel from 1990 (i.e., prior to the development of either drug formulation) to March 2015. Search terms used were "acromegaly and octreotide" and "acromegaly and lanreotide"; results were filtered for "clinical trial". Studies that were included had $\geq 10$ patients, a minimum duration of 24 weeks, used octreotide LAR or lanreotide Autogel as either first-line therapy or after previous surgery, radiotherapy or medical therapy, and reported GH and/or IGF-1 data as the primary objective of the study.

Of the 190 "clinical trials" found using "acromegaly and octreotide", 18 studies fulfilled our criteria for analysis (Table 1) [5-9, 11, 12, 14-19, 24-28]. Of the 83 "clinical trials" found using "acromegaly and lanreotide", 15 studies fulfilled our criteria for analysis (Table 2) [13, 14, 20-23, 29-36].

\section{Factors that may impact on response rates}

A recent meta-analysis by Carmichael et al. [37] that looked into how various aspects of acromegaly clinical trial methodology impact on reported response rates to somatostatin analogues concluded that year of publication, study duration and prior somatostatin analogue use significantly affected response rates. This analysis looked at how single factors might affect outcomes, rather than a combination of factors. There are many aspects to clinical studies that can potentially affect reported response rates, including the definition of response, the characteristics of the enrolled patients, whether or not all of the patients recruited into the study were included in the analysis, and whether the study was prospective or retrospective, among others. Most studies will be associated with a number of these factors, all of which can affect reported response rates.

\section{Patient population}

Clinical trials of any drug in any disease area select patients for enrollment into the study through a series of inclusion and exclusion criteria. These criteria are necessary to ensure that the correct patient population is treated for the hypothesis being examined, and in acromegaly may include such factors as sex, age, previous treatment history (e.g., transsphenoidal surgery, radiotherapy or medical therapy), and the presence or absence of other medical conditions.

Evaluating a drug effect in different subpopulations of patients with acromegaly may result in differing outcomes. In early studies of octreotide LAR and lanreotide Autogel, most studies included patients who were known responders to the drug (Tables 1,2). As octreotide LAR and lanreotide Autogel were new formulations of the available drugs, this inclusion criterion was chosen to show that the new formulations were as effective as the older formulations in order to gain market approval. However, if taken out of context, the reported response rates may appear relatively high when compared with more recent results in which patients were not selected for prior responsiveness. For example, early studies of octreotide LAR (Lancranjan et al. [8], [9]) and lanreotide Autogel (Caron et al. [29]), which included patients known to be responsive to subcutaneous (sc) octreotide immediate release and lanreotide slow release (SR), respectively, showed GH response rates of $55-69 \%[8,9,29]$ and IGF-1 response rates of 48-65\% $[8,9,29]$. Most of the patients in these studies had also received prior transsphenoidal surgery and/or radiotherapy.

More recently, somatostatin analogues have been evaluated as first-line therapy, in which the enrolled patients had not previously received any treatment for acromegaly. The percentage of patients achieving the composite endpoint of both GH and IGF-1 control after 1 year of treatment in prospective studies of patients with previously untreated acromegaly was $17-27 \%$ with octreotide LAR [16-18] and 33-54\% with lanreotide Autogel [22, 33]. Additionally, the recent randomized, double-blind study of pasireotide LAR versus octreotide LAR by Colao et al. [19] in patients who were either de novo or had received transsphenoidal surgery (but no medical therapy and no radiotherapy within 10 years) reported that $19 \%$ of octreotide LAR recipients and $31 \%$ of pasireotide LAR 


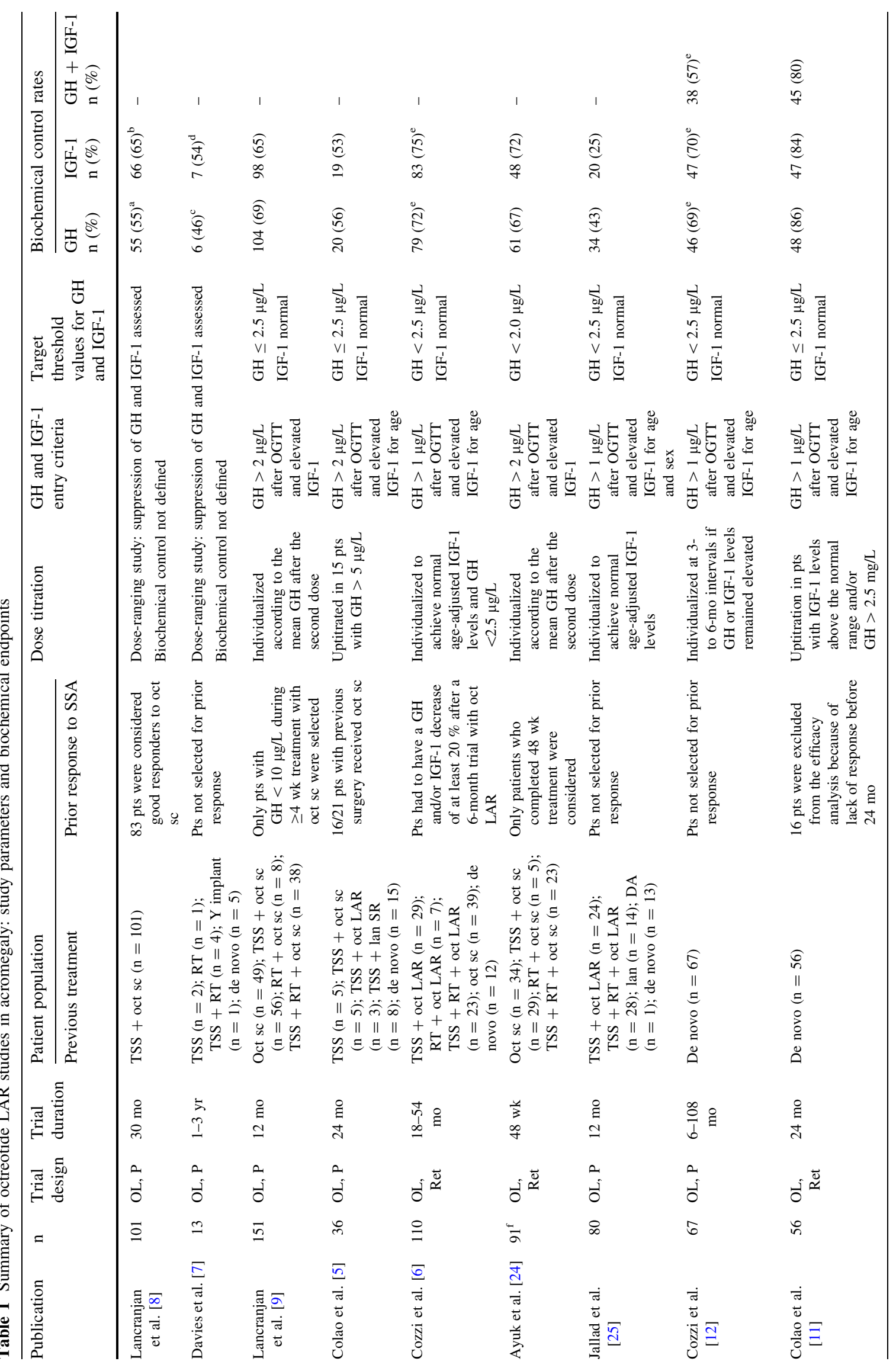




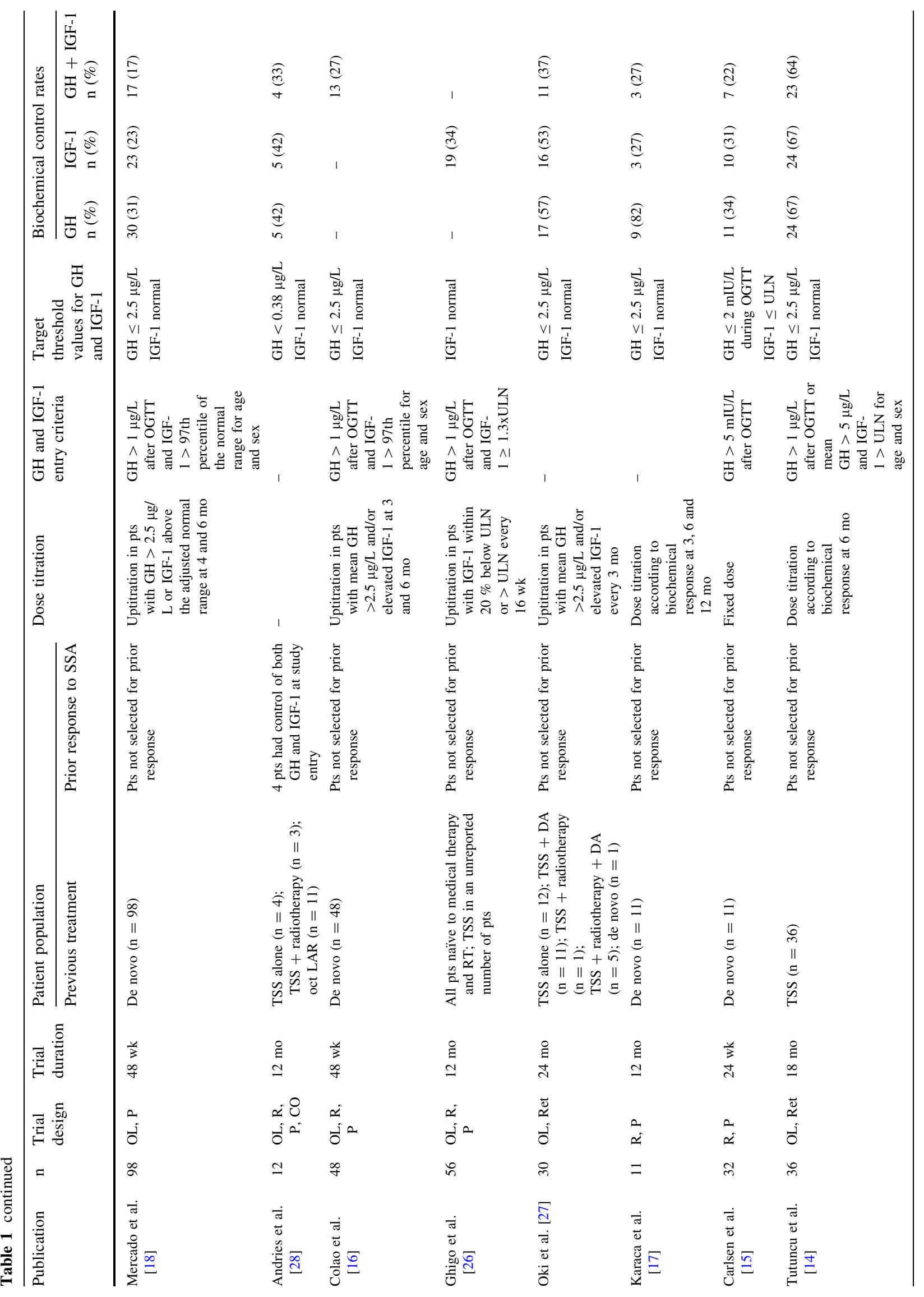




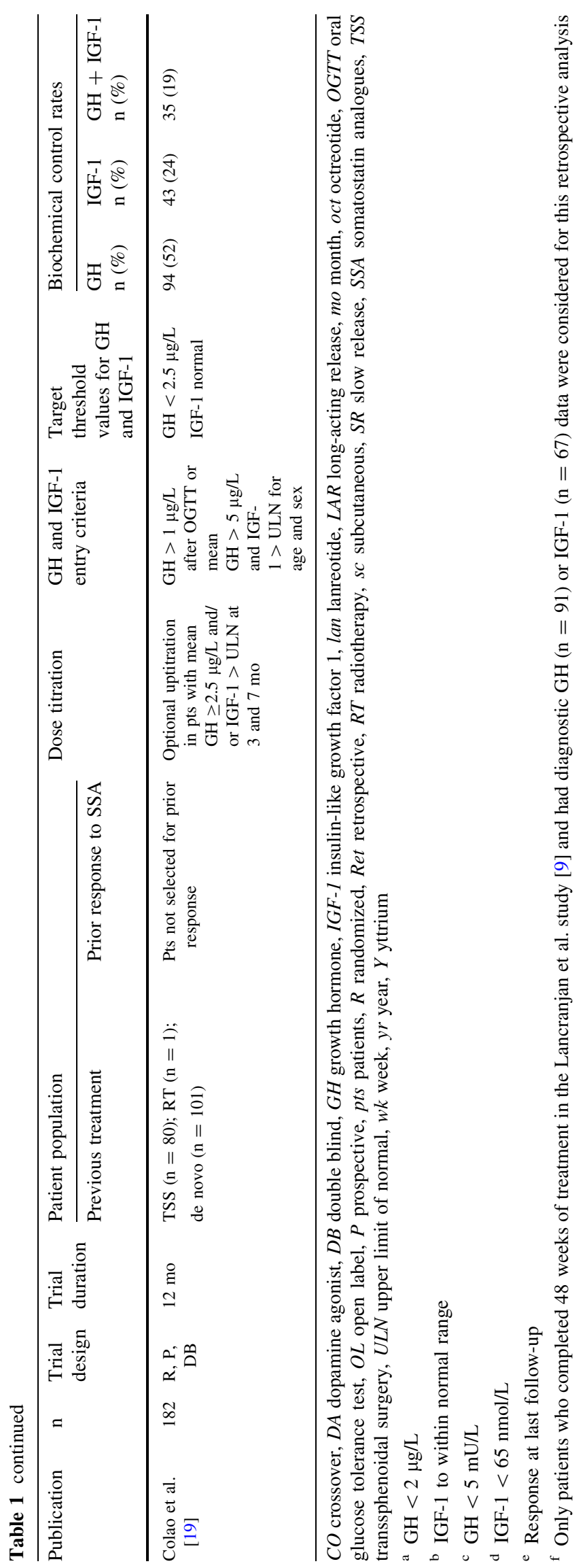









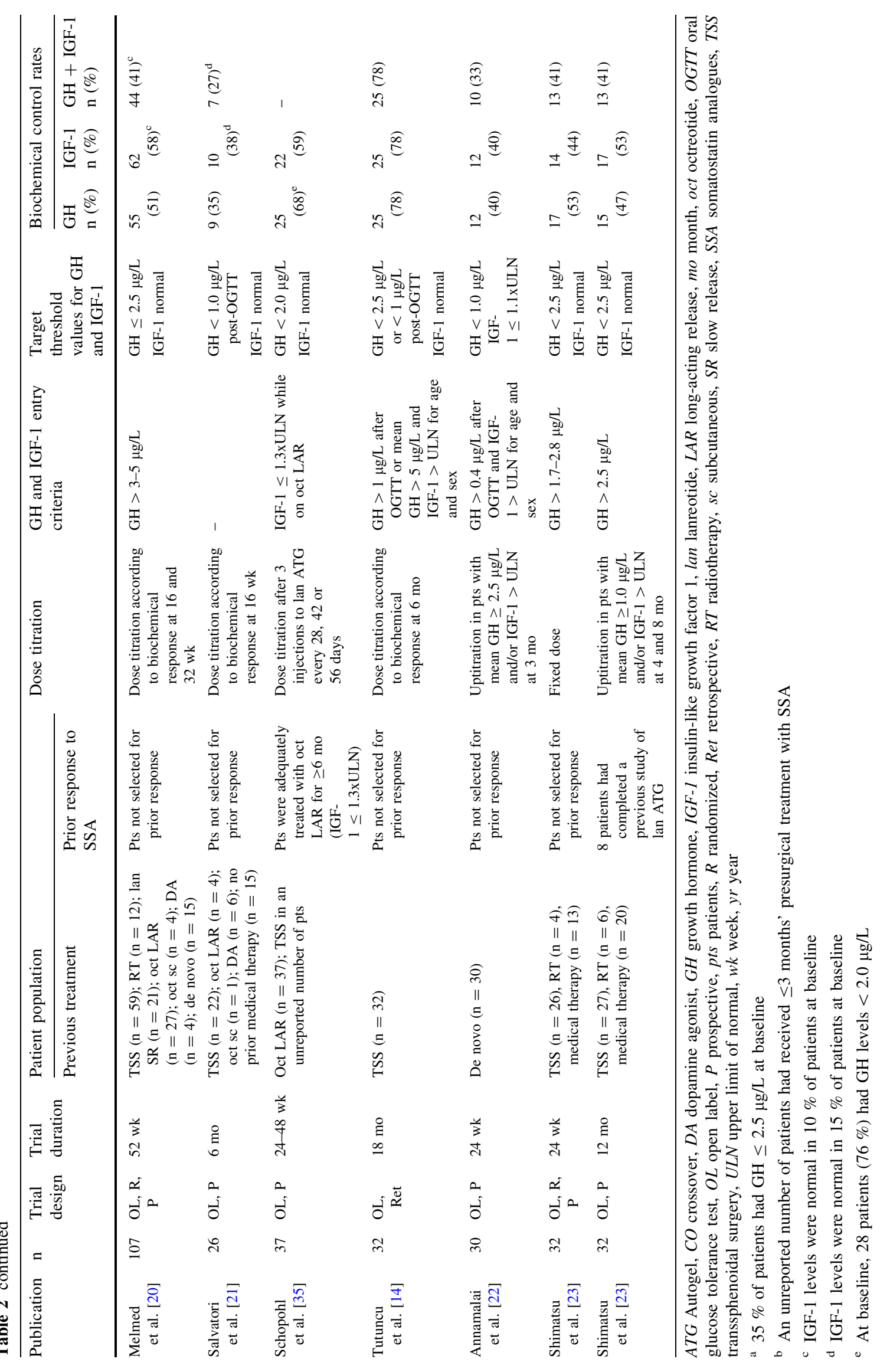


recipients achieved both GH and IGF-1 control after 1 year of treatment. When patients were stratified by prior treatment, the response rates in de novo patients were 17 and $26 \%$ for octreotide LAR and pasireotide LAR, respectively, compared with 22 and $39 \%$ in patients who had received prior surgery. Interestingly, in a 52-week study of lanreotide Autogel, $55 \%$ of patients who had received prior treatment with a somatostatin analogue achieved biochemical control, compared with $20 \%$ of somatostatinanalogue-naïve patients [20].

Although there are other factors that may have contributed to the relatively low response rates in these more recent studies, these results suggest that response rates in studies of patients with de novo acromegaly are generally lower than response rates in prospective studies of patients who have previously received transsphenoidal surgery and/ or radiotherapy and/or somatostatin analogues. This is consistent with a number of studies that showed that by reducing tumor mass and, therefore, decreasing basal GH secretion, subsequent control of GH and IGF-1 levels with somatostatin analogues may be improved [38-42].

\section{Heterogeneity in the definition of biochemical control}

The two parameters of biochemical control, suppression of excess GH secretion to predefined threshold levels and normalization of serum IGF-1 levels, are used as the primary markers of efficacy in most clinical trials of somatostatin analogues in patients with acromegaly. From the studies fulfilling the search criteria (Tables 1,2), target threshold levels are generally similar across all the studies (the majority use $\mathrm{GH} \leq 2.5 \mu \mathrm{g} / \mathrm{L}$ and normal IGF-1 for age and sex). However, studies published before 2006 generally reported response rates for GH and IGF-1 separately [5-9, 24, 25, 30], rather than the percentage of patients who achieved control of both GH and IGF-1 levels (Fig. 1).

Evaluation of GH or IGF-1 separately, rather than as a composite endpoint, was employed in 'early' clinical studies (1996-2006) [5-9, 24, 25, 30] and resulted in response rates that were relatively high compared with those in studies reported after 2006 (Fig. 1). The literature around this 'early' period began to report that patients with

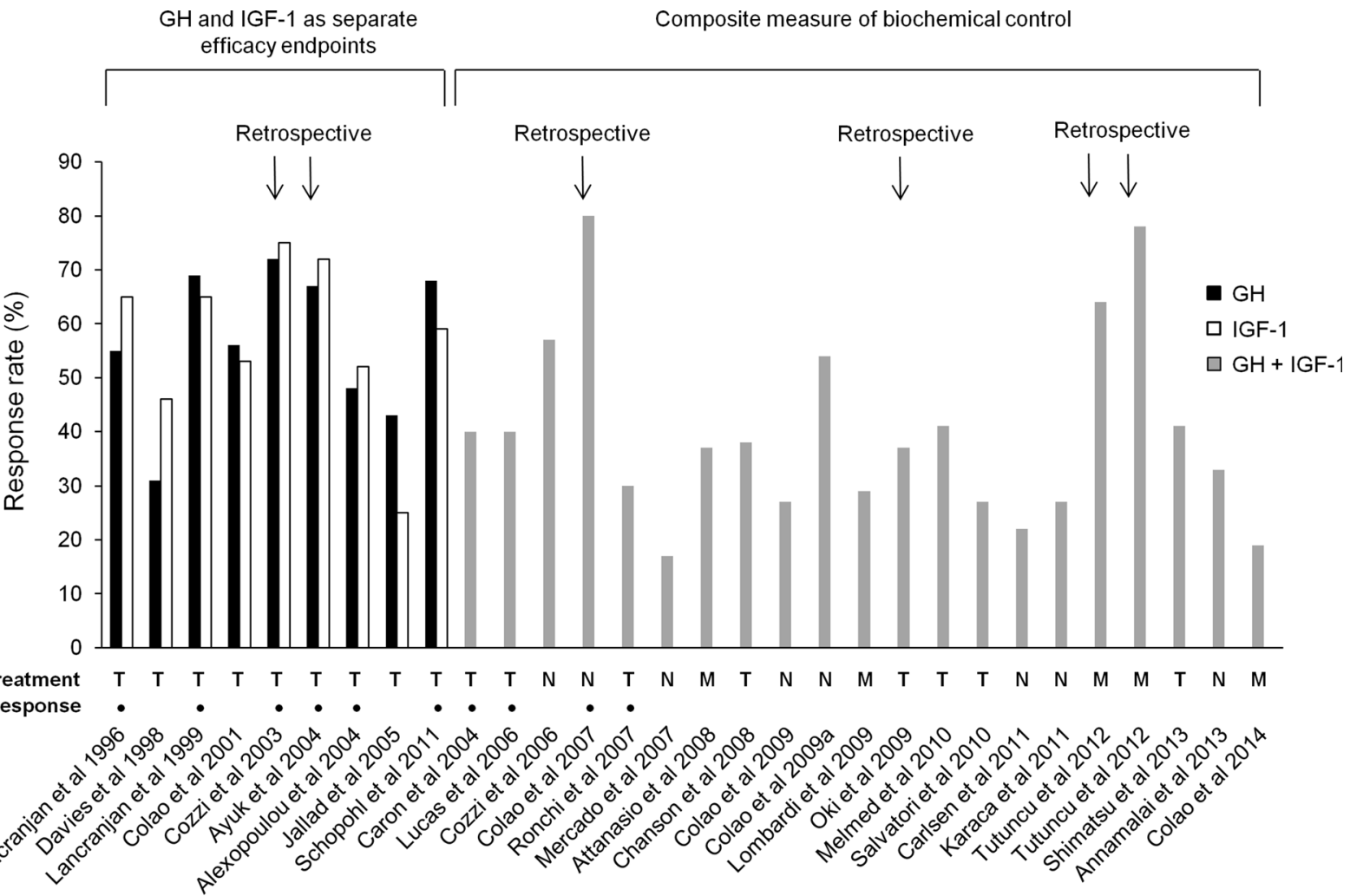

Fig. 1 Biochemical response rates to octreotide LAR and lanreotide Autogel reported in the medical literature by publication year and stratified according to whether GH and IGF-1 were reported as separate efficacy endpoints or as a composite efficacy endpoint.
$\mathrm{M}=$ prior surgery but medically naive; $\mathrm{N}=$ treatment naive; $\mathrm{T}=$ previously treated with surgery and/or radiotherapy and/or medical therapy 
GH levels $\leq 2.5 \mu \mathrm{g} / \mathrm{L}$ did not necessarily achieve normalization of IGF-1 levels [43]. Indeed, approximately $25 \%$ $[6,43]$ of patients were suggested to have discrepant GH and IGF-1 control (control of GH without IGF-1 control, or vice versa). As a consequence, the measurement of a composite efficacy endpoint of control of both GH and IGF-1 levels was advocated [44] and subsequently recommended by clinical practice guidelines for assessing biochemical response [1]. These findings likely prompted a shift away from only reporting GH and IGF-1 separately towards the more stringent composite measure and, as might be expected, the majority of the more recent studies (2007-2014) [6, 11, 12, 15-19] are generally associated with relatively low response rates (Fig. 1). Thus, heterogeneity in the definition of biochemical control may be a contributing factor giving rise to differences in reported response rates.

\section{Study design and nuances of the study protocol}

\section{Prospective versus retrospective}

Although both prospective and retrospective studies provide valuable data, retrospective studies are more likely to contain elements of bias and confounding. One of the main elements of bias associated with retrospective studies is the inclusion of only those patients who completed a certain duration of treatment and were not lost to follow-up or did not discontinue treatment because of adverse events or other reasons. For example, the retrospective study by Cozzi et al. [6], which reported a GH response rate of $72 \%$ and an IGF-1 response rate of $75 \%$, excluded an unreported number of patients who received octreotide LAR for less than 18 months. Had all patients who started on octreotide LAR been included in the analysis, the reported response rates may have been lower, as patients not reaching 18 months of therapy may have discontinued treatment because of non-response. Similarly, the retrospective comparison by Tutuncu et al. [14] of octreotide LAR and lanreotide Autogel in patients who had failed surgery reported that $64 \%$ of octreotide LAR patients and $78 \%$ of lanreotide Autogel patients had biochemical control after 18 months of treatment. However, the analysis retrospectively excluded all patients who had required a second operation or who had received additional medical treatment within 18 months of the initial surgery (i.e., probable non-responders to octreotide or lanreotide), thus artificially increasing response rates. As can be seen in Fig. 1, retrospective studies generally result in higher response rates, and the main reason is usually the retrospective exclusion of non-responders from the analysis.

\section{Per protocol or intention to treat}

However, many prospective studies also exclude patients who did not complete the study. For example, the prospective, 1-year follow-up study of lanreotide Autogel by Caron et al. [29] enrolled 130 patients previously treated with surgery and/or lanreotide Autogel, yet nine patients were excluded from the final analysis of biochemical control. Although the reasons for exclusion from the analysis may appear valid from a clinical practice perspective, for example, patients dropped out before the first efficacy analysis or withdrew consent to remain on treatment, these patients should be included as non-responders in an intention-to-treat (ITT) analysis. Therefore, although the study reported that $43 \%(52 / 121)$ of the ITT population achieved biochemical control [29], the actual response rate was $40 \%$ (52/130) (Table 2).

An efficacy analysis conducted on either the per-protocol (PP) or ITT population can produce significantly different outcomes. In an ITT analysis, all patients who were enrolled are considered part of the study, whether they receive treatment, complete the study or not. A PP analysis, however, is based on the population of patients who completed the clinical trial without any major protocol violations. For example, the study by Mercado et al. [18] reported results based on the PP population. This prospective, multicenter study evaluated octreotide LAR as first-line therapy in 98 previously untreated patients for 1 year. At month 12, 30 patients were excluded from the efficacy analysis because of either major protocol violations or early discontinuation; therefore, 68 patients formed the PP population. Seventeen patients achieved biochemical control $(\mathrm{GH} \leq 2.5 \mu \mathrm{g} / \mathrm{L}$ and normalization of IGF-1 levels), which corresponds to a response rate of $25 \%$ (17/ 68) based on the PP analysis, but $17.3 \%$ (17/98) based on analysis of the ITT population (Table 1). Thus, analysis of the PP population usually leads to the reporting of higher response rates than an analysis of all patients who were intended to be treated.

\section{Definition of responders and non-responders}

Open-ended studies that report patients' response at last follow-up generally result in a higher overall response rate than studies with a fixed time point to evaluate response. Although the definition of response may be the same with respect to the biochemical parameters (e.g., $\mathrm{GH} \leq 2.5 \mu \mathrm{g} /$ $\mathrm{L}$ and normal IGF-1), the time point at which biochemical control is measured may differ. In the study by Cozzi et al. [12], $56.7 \%$ of previously untreated patients were reported to have achieved biochemical control $(\mathrm{GH} \leq 2.5 \mu \mathrm{g} / \mathrm{L}$ and normal IGF-1). Patients in this study were followed up for 6-108 months, and their response at last follow-up was 
considered. As such, the $56.7 \%$ of patients who were considered responders had achieved a response at some point between months 6 and 108 and so should not be compared with studies of a similar patient population that reported response rates at a specific time point, for example, at month 12 of treatment.

Furthermore, the pre-specified definition of biochemical control should be adhered to during analysis of the results. Like most studies, the randomized, double-blind study of pasireotide LAR versus octreotide LAR by Colao et al. [19] defined biochemical control as $\mathrm{GH}<2.5 \mu \mathrm{g} / \mathrm{L}$ and normal IGF-1 at month 12. In this study, a patient with IGF-1 below the lower limit of normal was not considered a responder for the primary analysis because IGF-1 was abnormal. The consequence of this protocol definition is best exemplified by a post hoc analysis which included these patients with IGF-1 below the lower limit of normal as responders: response rates for octreotide LAR and pasireotide LAR increased from 19.2 to $20.9 \%$ and from 31.3 to $35.8 \%$, respectively [19]. These examples emphasize the importance of appreciating the definitions of responders in study protocols and how they are treated in the primary analysis.

\section{Assay variability}

A wide range of immunoassays are used for the assessment of GH and IGF-1 levels. However, considerable heterogeneity in assay characteristics exists, which may lead to variability in results. This assay variability can be largely classified into two categories: cross-sectional variation, where different assays give differing results [45, 46]; and longitudinal variation, in which assays are unstable over time [47]. The lack of standardization between assays is of such concern that a 2011 consensus statement on the standardization and evaluation of GH and IGF-1 assays was developed as part of an international effort to harmonize GH and IGF-1 assays [48]. For the purposes of the current review, an analysis of the assays used in each study has not been undertaken. However, it is likely that some of the variability in GH and IGF-1 response rates seen in studies in this review is due to assay variability.

\section{Response rates in a clinical trial setting: summary}

Using representative examples of different clinical trial protocols evaluating octreotide LAR and lanreotide Autogel as a treatment for acromegaly, it is evident that multiple factors are capable of impacting on reported response rates. Prospective studies reporting an ITT analysis that evaluated medically naïve patients, used the composite endpoint of both GH and IGF-1 control, and used a fixed time point to evaluate response were associated with lower response rates. The use of less stringent non-composite biochemical control endpoints, heterogeneous patient populations, study protocols that exclude treatment non-responders from the efficacy analysis, and prior responsiveness to medical therapy are just a few of the factors identified that likely contribute to higher success rates. This review does not attempt to place emphasis on any one particular factor over another, but it serves instead to raise awareness of the dangers of interpreting biochemical control response rates without first carefully considering how the study design, patient population and statistical analysis might impact on the data. Multivariate statistical analyses exploring the differences in response rates between studies would help to quantify the impact these factors may have on reported outcomes, and such an analysis is encouraged. With this in mind, it is perhaps unsurprising that response rates to somatostatin analogues, or to agents of any class of drug, in published clinical trials vary considerably.

\section{Response rates in clinical practice}

In clinical practice, biochemical response rates to somatostatin analogues are likely to fall somewhere between the rates observed in the early clinical trials and the rates observed in more recent trials. Many patients seen in the clinic are post-surgical or have had successful prior treatment with a somatostatin analogue, rather than being treatment naïve. Prior to treatment with somatostatin analogues, patients may also be 'pre-selected' for potential responsiveness with an acute octreotide suppression test [49]. The clinical setting allows for dose adjustments at the discretion of the physician and long-term treatment, both of which provide opportunities for higher response rates, similar to long-term, open-label studies. The choice of parameters used to gauge clinical response also plays a significant role in perceived treatment success; both GH and IGF-1 levels together as a composite measure should be used to assess biochemical response [2, 50].

Finally, similar to the differences in clinical trials of reporting data from patients who discontinue treatment (e.g., ITT vs. PP analysis), clinicians (including those from specialist pituitary centers) sometimes might remember only those patients who have responded to treatment, rather than those who have transitioned to another treatment or care provider. As a result, clinicians should be cautious of comparing response rates in real-world clinical scenarios with response rates obtained from a controlled trial setting.

As the mechanisms involved in the resistance to somatostatin analogues become better understood, it should 
be possible to predict which patients will respond to different medical therapies based on biomarkers. Therefore, a more successful outcome may be observed if individualized treatment is based on information such as the somatostatin receptor subtype profile, aryl hydrocarbon receptor-interacting protein (AIP) expression, and T2 intensity on magnetic resonance imaging, among others $[51,52]$. This would result in higher response rates, because those patients who would not have responded to treatment with a particular agent would not be unnecessarily treated.

\section{Concluding remarks}

As acromegaly is a rare disorder, even experienced endocrinologists may seldom treat a patient with acromegaly and therefore rely on the medical literature to inform treatment decision making. However, the wide range of reported response rates with octreotide LAR and lanreotide Autogel may be confusing and could lead to misinterpretation by both the patient and the physician in certain situations. Understanding the factors that potentially drive the discordance in response rates, as reported in this review, should allow clinicians to better gauge treatment expectations in specific patients.

Acknowledgments We thank Keri Wellington $\mathrm{PhD}$, Mudskipper Business Ltd, for medical editorial assistance with this manuscript.

Funding Financial support for medical editorial assistance was provided by Novartis Pharmaceuticals Corporation.

\section{Compliance with ethical standards}

Conflict of interest RSA and LK have nothing to disclose. AC has been principal investigator of Novartis, Ipsen and Pfizer research studies, has received research grants from Novartis, Ipsen, Pfizer, Ferring, Lilly, Novo Nordisk, HRA Pharma and Italfarmaco, has been an occasional consultant for Novartis, Ipsen, Pfizer and Italfarmaco, and has received lecture fees and honoraria from Novartis and Ipsen. RP has been principal investigator of Novartis research studies, has received research grants from Novartis, Pfizer, Viropharma and IBSA, has been an occasional consultant for Novartis, Ipsen, Pfizer, Viropharma, Ferring and Italfarmaco, and has received lecture fees and honoraria from Novartis. MRG has received research grants from Novartis and Pfizer, has been principal investigator for Novartis and Ipsen clinical trials, has served on advisory boards for Novartis, and has received lecture fees from Novartis, Ipsen and Pfizer.

Open Access This article is distributed under the terms of the Creative Commons Attribution 4.0 International License (http://crea tivecommons.org/licenses/by/4.0/), which permits unrestricted use, distribution, and reproduction in any medium, provided you give appropriate credit to the original author(s) and the source, provide a link to the Creative Commons license, and indicate if changes were made.

\section{References}

1. Melmed S, Colao A, Barkan A, Molitch M, Grossman AB, Kleinberg D, Clemmons D, Chanson P, Laws E, Schlechte J, Vance ML, Ho K, Giustina A (2009) Guidelines for acromegaly management: an update. J Clin Endocrinol Metab 94(5):15091517

2. Katznelson L, Atkinson JL, Cook DM, Ezzat SZ, Hamrahian AH, Miller KK (2011) American Association of Clinical Endocrinologists medical guidelines for clinical practice for the diagnosis and treatment of acromegaly-2011 update. Endocr Pract 17(Suppl 4):1-44

3. Katznelson L, Laws ER Jr, Melmed S, Molitch ME, Murad MH, Utz A, Wass JA (2014) Acromegaly: an endocrine society clinical practice guideline. J Clin Endocrinol Metab 99(11):39333951

4. Colao A, Auriemma RS, Lombardi G, Pivonello R (2011) Resistance to somatostatin analogs in acromegaly. Endocr Rev 32(2):247-271

5. Colao A, Ferone D, Marzullo P, Cappabianca P, Cirillo S, Boerlin V, Lancranjan I, Lombardi G (2001) Long-term effects of depot long-acting somatostatin analog octreotide on hormone levels and tumor mass in acromegaly. J Clin Endocrinol Metab 86(6): 2779-2786

6. Cozzi R, Attanasio R, Montini M, Pagani G, Lasio G, Lodrini S, Barausse M, Albizzi M, Dallabonzana D, Pedroncelli AM (2003) Four-year treatment with octreotide-long-acting repeatable in 110 acromegalic patients: predictive value of short-term results? J Clin Endocrinol Metab 88(7):3090-3098

7. Davies PH, Stewart SE, Lancranjan L, Sheppard MC, Stewart PM (1998) Long-term therapy with long-acting octreotide (Sandostatin-LAR) for the management of acromegaly. Clin Endocrinol (Oxf) 48(3):311-316

8. Lancranjan I, Bruns C, Grass P, Jaquet P, Jervell J, KendallTaylor P, Lamberts SW, Marbach P, Orskov H, Pagani G, Sheppard M, Simionescu L (1996) Sandostatin ${ }^{\circledR} \operatorname{LAR}^{\circledR}$ : a promising therapeutic tool in the management of acromegalic patients. Metabolism 45(8 Suppl 1):67-71

9. Lancranjan I, Atkinson AB (1999) Results of a European multicentre study with Sandostatin ${ }^{\circledR}$ LAR $^{\circledR}$ in acromegalic patients. Sandostatin LAR Group. Pituitary 1(2):105-114

10. Freda PU, Katznelson L, van der Lely AJ, Reyes CM, Zhao S, Rabinowitz D (2005) Long-acting somatostatin analog therapy of acromegaly: a meta-analysis. J Clin Endocrinol Metab 90(8): 4465-4473

11. Colao A, Pivonello R, Auriemma RS, Galdiero M, Savastano S, Lombardi G (2007) Beneficial effect of dose escalation of octreotide-LAR as first-line therapy in patients with acromegaly. Eur J Endocrinol 157(5):579-587

12. Cozzi R, Montini M, Attanasio R, Albizzi M, Lasio G, Lodrini S, Doneda P, Cortesi L, Pagani G (2006) Primary treatment of acromegaly with octreotide LAR: a long-term (up to 9 years) prospective study of its efficacy in the control of disease activity and tumor shrinkage. J Clin Endocrinol Metab 91(4):1397-1403

13. Chanson P, Borson-Chazot F, Kuhn J-M, Blumberg J, Maisonobe P, Delemer B (2008) Control of IGF-I levels with titrated dosing of lanreotide Autogel over 48 weeks in patients with acromegaly. Clin Endocrinol (Oxf) 69(2):299-305

14. Tutuncu Y, Berker D, Isik S, Ozuguz U, Akbaba G, Kucukler FK, Aydin Y, Guler S (2012) Comparison of octreotide LAR and lanreotide autogel as post-operative medical treatment in acromegaly. Pituitary 15(3):398-404

15. Carlsen SM, Svartberg J, Schreiner T, Aanderud S, Johannesen O, Skeie S, Lund-Johansen M, Fougner SL, Bollerslev J (2011) Six-month preoperative octreotide treatment in unselected, de 
novo patients with acromegaly: effect on biochemistry, tumour volume, and postoperative cure. Clin Endocrinol (Oxf) 74(6): 736-743

16. Colao A, Cappabianca P, Caron P, De MenismE, Farrall AJ, Gadelha MR, Hmissi A, Rees A, Reincke M, Safari M, T'Sjoen G, Bouterfa H, Cuneo RC (2009) Octreotide LAR vs. surgery in newly diagnosed patients with acromegaly: a randomized, openlabel, multicentre study. Clin Endocrinol (Oxf) 70(5):757-768

17. Karaca Z, Tanriverdi F, Elbuken G, Cakir I, Donmez H, Selcuklu A, Durak A, Dokmetas H, Colak R, Unluhizarci K, Kelestimur F (2011) Comparison of primary octreotide-LAR and surgical treatment in newly diagnosed patients with acromegaly. Clin Endocrinol (Oxf) 75(5):678-684

18. Mercado M, Borges F, Bouterfa H, Chang T-C, Chervin A, Farrall AJ, Patocs A, Petersenn S, Podoba J, Safari M, Wardlaw J (2007) A prospective, multicentre study to investigate the efficacy, safety and tolerability of octreotide LAR $^{\circledR}$ (long-acting repeatable octreotide) in the primary therapy of patients with acromegaly. Clin Endocrinol (Oxf) 66(6):859-868

19. Colao A, Bronstein MD, Freda P, Gu F, Shen C-C, Gadelha M, Fleseriu M, van der Lely AJ, Farrall AJ, Hermosillo Reséndiz K, Ruffin M, Chen Y, Sheppard M (2014) Pasireotide versus octreotide in acromegaly: a head-to-head superiority study. J Clin Endocrinol Metab 99(3):791-799

20. Melmed S, Cook D, Schopohl J, Goth MI, Lam KS, Marek J (2010) Rapid and sustained reduction of serum growth hormone and insulin-like growth factor-1 in patients with acromegaly receiving lanreotide Autogel ${ }^{\circledR}$ therapy: a randomized, placebocontrolled, multicenter study with a 52 week open extension. Pituitary 13(1):18-28

21. Salvatori R, Nachtigall LB, Cook DM, Bonert V, Molitch ME, Blethen S, Chang S (2010) Effectiveness of self- or partner-administration of an extended-release aqueous-gel formulation of lanreotide in lanreotide-naive patients with acromegaly. Pituitary 13(2):115-122

22. Annamalai AK, Webb A, Kandasamy N, Elkhawad M, Moir S, Khan F, Maki-Petaja K, Gayton EL, Strey CH, O'Toole S, Ariyaratnam S, Halsall DJ, Chaudhry AN, Berman L, Scoffings DJ, Antoun NM, Dutka DP, Wilkinson IB, Shneerson JM, Pickard JD, Simpson HL, Gurnell M (2013) A comprehensive study of clinical, biochemical, radiological, vascular, cardiac, and sleep parameters in an unselected cohort of patients with acromegaly undergoing presurgical somatostatin receptor ligand therapy. J Clin Endocrinol Metab 98(3):1040-1050

23. Shimatsu A, Teramoto A, Hizuka N, Kitai K, Ramis J, Chihara K (2013) Efficacy, safety, and pharmacokinetics of sustained-release lanreotide (lanreotide Autogel) in Japanese patients with acromegaly or pituitary gigantism. Endocr J 60(5):651-663

24. Ayuk J, Stewart SE, Stewart PM, Sheppard MC (2004) Efficacy of Sandostatin LAR (long-acting somatostatin analogue) is similar in patients with untreated acromegaly and in those previously treated with surgery and/or radiotherapy. Clin Endocrinol (Oxf) 60(3):375-381

25. Jallad RS, Musolino NR, Salgado LR, Bronstein MD (2005) Treatment of acromegaly with octreotide-LAR: extensive experience in a Brazilian institution. Clin Endocrinol (Oxf) 63(2): $168-175$

26. Ghigo E, Biller BM, Colao A, Kourides IA, Rajicic N, Hutson RK, De ML, Klibanski A (2009) Comparison of pegvisomant and longacting octreotide in patients with acromegaly naive to radiation and medical therapy. J Endocrinol Invest 32(11):924-933

27. Oki Y, Inoue T, Imura M, Tanaka T, Genma R, Iwabuchi M, Hataya Y, Matsuzawa Y, Iino K, Nishizawa S, Nakamura H (2009) Investigation into the efficacy and safety of octreotide LAR in Japanese patients with acromegaly: Shizuoka study. Endocr J 56(9):1095-1101
28. Andries M, Glintborg D, Kvistborg A, Hagen C, Andersen M (2008) A 12-month randomized crossover study on the effects of lanreotide Autogel and octreotide long-acting repeatable on $\mathrm{GH}$ and IGF-1 in patients with acromegaly. Clin Endocrinol (Oxf) 68(3):473-480

29. Caron P, Bex M, Cullen DR, Feldt-Rasmussen U, Pico Alfonso AM, Pynka S, Racz K, Schopohl J, Tabarin A, Valimaki MJ (2004) One-year follow-up of patients with acromegaly treated with fixed or titrated doses of lanreotide Autogel. Clin Endocrinol (Oxf) 60(6):734-740

30. Alexopoulou O, Abrams P, Verhelst J, Poppe K, Velkeniers B, Abs R, Maiter D (2004) Efficacy and tolerability of lanreotide Autogel therapy in acromegalic patients previously treated with octreotide LAR. Eur J Endocrinol 151(3):317-324

31. Ronchi CL, Boschetti M, Uberti EC, Mariotti S, Grottoli S, Loli P, Lombardi G, Tamburrano G, Arvigo M, Angeletti G, Boscani PF, Beck-Peccoz P, Arosio M (2007) Efficacy of a slow-release formulation of lanreotide (Autogel $120 \mathrm{mg}$ ) in patients with acromegaly previously treated with octreotide long acting release (LAR): an open, multicentre longitudinal study. Clin Endocrinol (Oxf) 67(4):512-519

32. Attanasio R, Lanzi R, Losa M, Valentini F, Grimaldi F, De Menis E, Davi MV, Battista C, Castello R, Cremonini N, Razzore P, Rosato F, Montini M, Cozzi R (2008) Effects of lanreotide Autogel on growth hormone, insulinlike growth factor 1 , and tumor size in acromegaly: a 1-year prospective multicenter study. Endocr Pract 14(7):846-855

33. Colao A, Auriemma RS, Rebora A, Galdiero M, Resmini E, Minuto F, Lombardi G, Pivonello R, Ferone D (2009) Significant tumour shrinkage after 12 months of lanreotide Autogel-120 mg treatment given first-line in acromegaly. Clin Endocrinol (Oxf) 71(2):237-245

34. Lombardi G, Minuto F, Tamburrano G, Ambrosio MR, Arnaldi G, Arosio M, Chiarini V, Cozzi R, Grottoli S, Mantero F, Bogazzi F, Terzolo M, Tita P, Boscani PF, Colao A (2009) Efficacy of the new long-acting formulation of lanreotide (lanreotide Autogel) in somatostatin analogue-naive patients with acromegaly. J Endocrinol Invest 32(3):202-209

35. Schopohl J, Strasburger CJ, Caird D, Badenhoop K, Beuschlein F, Droste M, Plockinger U, Petersenn S (2011) Efficacy and acceptability of Lanreotide Autogel ${ }^{\circledR} 120 \mathrm{mg}$ at different dose intervals in patients with acromegaly previously treated with Octreotide LAR. Exp Clin Endocrinol Diabetes 119(3):156-162

36. Lucas T, Astorga R, The Spanish-Portuguese Multicentre Autogel Study Group on Acromegaly (2006) Efficacy of lanreotide Autogel administered every 4-8 weeks in patients with acromegaly previously responsive to lanreotide microparticles $30 \mathrm{mg}$ : a phase III trial. Clin Endocrinol (Oxf) 65(3):320-326

37. Carmichael JD, Bonert VS, Nuño M, Ly D, Melmed S (2014) Acromegaly clinical trial methodology impact on reported biochemical efficacy rates of somatostatin receptor ligand treatments-a metaanalysis. J Clin Endocrinol Metab 99(5):1825-1833

38. Colao A, Attanasio R, Pivonello R, Cappabianca P, Cavallo LM, Lasio G, Lodrini A, Lombardi G, Cozzi R (2006) Partial surgical removal of GH-secreting pituitary tumors enhances the response to somatostatin analogues in acromegaly. J Clin Endocrinol Metab 91(1):85-92

39. Karavitaki N, Turner HE, Adams CB, Cudlip S, Byrne JV, FazalSanderson V, Rowlers S, Trainer PJ, Wass JA (2008) Surgical debulking of pituitary macroadenomas causing acromegaly improves control by lanreotide. Clin Endocrinol (Oxf) 68(6):970-975

40. Petersenn S, Buchfelder M, Reincke M, Strasburger CM, Franz H, Lohmann R, Quabbe HJ, Plockinger U (2008) Results of surgical and somatostatin analog therapies and their combination in acromegaly: a retrospective analysis of the German Acromegaly Register. Eur J Endocrinol 159(5):525-532 
41. Petrossians P, Borges-Martins L, Espinoza C, Daly A, Betea D, Valdes-Socin H, Stevenaert A, Chanson P, Beckers A (2005) Gross total resection or debulking of pituitary adenomas improves hormonal control of acromegaly by somatostatin analogs. Eur J Endocrinol 152(1):61-66

42. Jallad RS, Musolino NR, Kodaira S, Cescato VA, Bronstein MD (2007) Does partial surgical tumour removal influence the response to octreotide-LAR in acromegalic patients previously resistant to the somatostatin analogue? Clin Endocrinol (Oxf) 67(2):310-315

43. Vierhapper H, Heinze G, Gessl A, Exner M, Bieglmayr C (2003) Use of the oral glucose tolerance test to define remission in acromegaly. Metabolism 52(2):181-185

44. Freda PU (2003) Current concepts in the biochemical assessment of the patient with acromegaly. Growth Horm IGF Res 13(4):171-184

45. Krebs A, Wallaschofski H, Spilcke-Liss E, Kohlmann T, Brabant G, Volzke H, Nauck M (2008) Five commercially available insulin-like growth factor I (IGF-I) assays in comparison to the former Nichols Advantage IGF-I in a growth hormone treated population. Clin Chem Lab Med 46(12):1776-1783

46. Muller A, Scholz M, Blankenstein O, Binder G, Pfaffle R, Korner A, Kiess W, Heider A, Bidlingmaier M, Thiery J, Kratzsch J (2011) Harmonization of growth hormone measurements with different immunoassays by data adjustment. Clin Chem Lab Med 49(7):1135-1142
47. Algeciras-Schimnich A, Bruns DE, Boyd JC, Bryant SC, La Fortune KA, Grebe SK (2013) Failure of current laboratory protocols to detect lot-to-lot reagent differences: findings and possible solutions. Clin Chem 59(8):1187-1194

48. Clemmons DR (2011) Consensus statement on the standardization and evaluation of growth hormone and insulin-like growth factor assays. Clin Chem 57(4):555-559

49. Bandgar TR, Sarathi V, Shivane V, Bansode N, Menon PS, Shah NS (2010) The value of an acute octreotide suppression test in predicting response to long-term somatostatin analogue therapy in patients with acromegaly. J Postgrad Med 56(1):7-11

50. Giustina A, Chanson P, Kleinberg D, Bronstein MD, Clemmons DR, Klibanski A, van der Lely AJ, Strasburger CJ, Lamberts SW, Ho KK, Casanueva FF, Melmed S (2014) Expert consensus document: a consensus on the medical treatment of acromegaly. Nat Rev Endocrinol 10(4):243-248

51. Gadelha MR, Kasuki L, Korbonits M (2013) Novel pathway for somatostatin analogs in patients with acromegaly. Trends Endocrinol Metab 24(5):238-246

52. Kasuki L, Vieira NL, Wildemberg LE, Colli LM, de Takiya CM, Gadelha MR (2012) AIP expression in sporadic somatotropinomas is a predictor of the response to octreotide LAR therapy independent of SSTR2 expression. Endocr Relat Cancer 19(3):L25-L29 